\title{
Controlled trial of azathioprine in chronic ulcerative colitis
}

\author{
A P KIRK, J E LENNARD-JONES
}

\begin{abstract}
A double-blind controlled trial of azathioprine in a dose of $2-2.5 \mathrm{mg} / \mathrm{kg}$ body weight over six months was conducted among 44 patients with active chronic ulcerative colitis. Three patients treated with placebo did not complete the trial because their disease became so severe that colectomy was performed. Among patients who completed the trial the mean dose of prednisolone necessary to control the disease decreased in those treated with azathioprine and those treated with placebo; the reduction was greater among those who took azathioprine $(p<0.001)$. Activity of the disease apparently improved in both treatment groups but a significant $(p<0.001)$ trend was observed only in those patients treated with azathioprine. No serious side effects from azathioprine occurred during the trial but seven of 24 patients had to stop the drug because of nausea.

Azathioprine may have a role in the treatment of a few patients with troublesome chronic colitis for whom conventional drug treatment is ineffectual, or for whom continuous systemic corticosteroid treatment is needed to control symptoms, and for whom surgical treatment is inappropriate.
\end{abstract}

\section{Introduction}

Some patients with ulcerative colitis experience persistent and disabling symptoms due to active chronic inflammation which is resistant to treatment. Symptoms can sometimes be partially controlled by prolonged systemic or topical treatment with corticosteroids. Uncontrolled trials have suggested that azathioprine may benefit patients with this form of colitis. The only two controlled trials have failed to show an effect of the drug on inflammation, though one showed a steroid-sparing effect ${ }^{1}$ and the other a possible decrease in relapse rate in established disease. $^{2}$

St Mark's Hospital, London EC1V 2PS

A P KIRK, BSC, MRCP, research fellow

J E LENNARD-JONES, MD, FRCP, professor of gastroenterology
We report a double-blind controlled trial of azathioprine in patients with active chronic ulcerative colitis which was apparently unresponsive to corticosteroid treatment.

\section{Patients and methods}

The protocol was approved by the St Mark's Hospital ethical committee and all patients gave informed consent. Forty-four patients entered the trial and were prescribed either azathioprine $2-2.5 \mathrm{mg} / \mathrm{kg}$ (24 patients) or placebo (20 patients), in addition to their regular treatment, for six months. During this time clinical activity was assessed at monthly intervals by a clinical score sheet recording symptoms, signs, sigmoidoscopic findings, and biochemical and haematological results. ${ }^{3}$

Throughout the trial we attempted to reduce the dose of corticosteroid in all patients as far as estimates of clinical activity permitted. Observations were continued for three months after azathioprine and placebo treatment had been stopped.

Fifteen patients were withdrawn from the trial, nine because of side effects (nausea in seven patients treated with azathioprine and skin reactions in two treated with the placebo); one patient receiving azathioprine died of a myocardial infarction; five patients failed to comply within the first month but these patients had no side effects (one azathioprine, four placebo). Among the remaining patients the study was terminated early (at one, three, and four months) in three of 14 receiving placebo treatment because the severity of the disease necessitated surgical treatment. All 15 patients treated with azathioprine completed the trial. The two groups did not differ in mean age (azathioprine group, 50 years; placebo group, 49 years), sex ratio, the extent (in the azathioprine and placebo groups eight and six patients respectively had total inflammation and seven and eight patients respectively had distal inflammation) or activity of the disease, or initial dose of steroids; but the mean duration of disease did vary (azathioprine group, 15 years; placebo group, eight years).

\section{Results}

The table shows that azathioprine exerted a steroid-sparing effect, which was evident at three and pronounced at six months. When directly compared the activity scores in the two groups showed no difference.

When each group was analysed separately, however, the reduction in activity score within the azathioprine group was significant $(p<0.001)$ at three and six months when initial and later values were compared by Student's paired $t$ test. The reduction in activity score 
in the placebo group took no account of one patient treated surgically in the first three months or of two patients operated on during the second three months; among the other patients the mean improvement did not reach statistical significance. Withdrawal of the test drug was associated with worsening of the activity score over three months in 10 of 15 patients treated with azathioprine compared with four of the remaining 11 patients in the placebo group.

\section{Discussion}

The mean dose of prednisolone necessary to control activity of the disease decreased both in patients treated with azathioprine and in those receiving a placebo; the dose needed at six months was less $(p<0.001)$ in the former than in the latter group. This greater steroid-sparing effect of azathioprine over dangerous reactions were observed, though nausea prevented seven of 24 patients from completing the trial. Any patient treated with azathioprine requires careful and regular supervision.

The use of azathioprine in colitis should be restricted to patients with troublesome disease for whom conventional drug treatment proves unsuccessful, or for whom continuous systemic corticosteroid treatment is needed to control symptoms, and for whom surgical treatment is inappropriate.

APK was supported by the St Mark's Research Foundation. We thank our colleagues in the colitis clinic for their help and Miss Brenda Roach for secretarial help.

Correspondence and requests for reprints should be sent to: Professor J E Lennard-Jones, St Mark's Hospital, City Road, London EC1V 2PS.

Assessment of clinical activity of ulcerative colitis in patients treated either with azathioprine or placebo according to activity score and reduction in daily dose of prednisolone

\begin{tabular}{|c|c|c|c|c|c|c|c|c|}
\hline \multirow{2}{*}{$\begin{array}{l}\text { Treatment } \\
\text { group }\end{array}$} & \multicolumn{4}{|c|}{ Mean activity score } & \multicolumn{4}{|c|}{ Dose of prednisolone (mg daily) } \\
\hline & Initial & 3 Months & 6 Months & $\begin{array}{l}3 \text { Months } \\
\text { after trial }\end{array}$ & Initial & 3 Months & 6 Months & $\begin{array}{l}3 \text { Months } \\
\text { after trial }\end{array}$ \\
\hline $\begin{array}{l}\text { Azathioprine } \\
\text { Placebo }\end{array}$ & $\begin{array}{l}8 \cdot 1 \\
7 \cdot 7\end{array}$ & $\begin{array}{l}4 \cdot 3^{\mathrm{a}} \\
4 \cdot 9^{\mathrm{d}}\end{array}$ & $\begin{array}{l}4 \cdot 2^{\mathrm{a}} \\
5 \cdot 3^{\mathrm{d}}\end{array}$ & $\begin{array}{l}6 \cdot 6^{d} \\
5 \cdot 8^{d}\end{array}$ & $\begin{array}{l}22 \cdot 2 \\
23 \cdot 2\end{array}$ & $\begin{array}{l}10 \cdot 2^{\mathrm{b}} \\
17 \cdot 7^{\mathrm{d}}\end{array}$ & $\begin{array}{r}2 \cdot 3^{\mathrm{a} * *} \\
13 \cdot 6^{\mathrm{c} * *}\end{array}$ & $\begin{array}{r}6 \cdot 7^{\mathrm{b} *} \\
17 \cdot 7^{\mathrm{d} *}\end{array}$ \\
\hline
\end{tabular}

Comparison between groups (Student's $t$ test): ${ }^{* *} \mathrm{p}<0.001 ;^{*} \mathrm{p}<0.02$

Comparison with initial readings in each group (Student's paired $t$ test): ${ }^{\mathrm{a}} \mathrm{p}<0.001 ;{ }^{\mathrm{b}} \mathrm{p}<0.01 ;{ }^{\mathrm{c}} \mathrm{p} \cdot 0.02 ;{ }^{\mathrm{d}}$ Not significant.

a placebo is consistent with reports of other trials in ulcerative colitis and Crohn's disease. ${ }^{14}$

The activity of the colitis, as judged by a numerical score, improved $(p<0.001)$ in the group given azathioprine. Changes in disease activity in the placebo group are less easy to interpret because in three patients the disease became so severe that colectomy was performed; none of the patients who became worse contributed to the reduced mean score at six months. Even among the patients who continued medical treatment the change in score showed no significant trend. These results support the possibility that azathioprine suppresses inflammation, though the effect may be slow and difficult to substantiate.

Azathioprine in the dose used here can cause bone marrow depression and other serious side effects. ${ }^{5}$ In this small series no

\section{References}

${ }^{1}$ Rosenberg JL, Wall AJ, Levin B, Binder HJ, Kirsner JB. A controlled trial of azathioprine in the management of chronic ulcerative colitis. Gastroenterology $1975 ; 69: 96-9$.

2 Jewell DP, Truelove SC. Azathioprine in ulcerative colitis: final report on controlled therapeutic trial. Br Med 7 1974;iv:627-30.

${ }^{3}$ Powell-Tuck J, Bown R, Lennard-Jones JE. Comparison of oral prednisolone given as single or multiple daily dosès for active proctocolitis. Scand f Gastroenterol 1978;13:833-7.

${ }^{4}$ Rosenberg JL, Levin B, Wall AJ, Kirsner JB. A controlled trial of azathioprine in Crohn's disease. Digestive Diseases 1975;20:721-6.

${ }^{5}$ Singleton JW, Law DH, Kelley ML Jr, Mekhjian HS, Sturdevant RAL. National Co-operative Crohn's Disease Study: adverse reactions to study drugs. Gastroenterology 1979;77:870-82.

(Accepted 11 February 1982)
OF all difeafes incident to mankind, thofe of the nervous kind are the moft complicated and difficult to cure. A volume would not be fufficient to point out their various appearances. They imitate almoft every difeafe; and are feldom alike in two different perfons, or even in the fame perfon at different times. Proteus-like, they are continually changing fhape; and upon every fref $h$ attack, the patient thinks he feels fymptoms which he never experienced before. Nor do they only affect the body; the mind likewife fuffers, and is often thereby rendered extremely weak and peevifh. The low fpirits, timoroufnefs, melancholy, and ficklenefs of temper, which generally attend nervous diforders, induce many to believe, that they are entirely difeafes of the mind; but this change of temper is rather a confequence, than the caufe of nervous difeafes.

CAUSES. - Every thing that tends to relax or weaken the body, difpofes it to nervous difeafes, as indolence, exceffive venery, drinking too much tea, or other weak watery liquors, frequent bleeding, purging, vomiting, \&c. Whatever hurts the digeftion, or prevents the proper affimilation of the food, has likewife this effect; as long fafting, excefs in eating or drinking, the ufe of windy, crude, or unwholefome aliments, an unfavourable pofture of the body, \&c.

Nervous diforders often proceed from intenfe application to ftudy. Indeed few ftudious perfons are entirely free from them. Nor is this at all to be wondered at; intenfe thinking not only preys upon the fpirits, but prevents the perfon from taking proper exercife, by which means the digeftion is impaired, the nourifhment prevented, the folids relaxed, and the whole mafs of humours vitiated. Grief and difappointment likewife produce the fame effects. I have known more nervous patients, who dated the commencement of their diforders from the lofs of a hulband, a favourite child, or from fome difappointment in life, than from any other caufe. In a word, whatever weakens the body, or depreffes the fpirits, may occafion nervous diforders, as unwholefome air, want of fleep, great fatigue, difagreeable apprehenfions, anxiety, vexation, \&c.

(Buchan's Domestic Medicine, 1786.) 